\title{
Developing a Scenic Design Portfolio
}

\section{Kathryn Elizabeth Springmann Metairie, Louisiana}

Bachelor of Science, Northwestern State University of Louisiana, 2009

A Thesis presented to the Graduate Faculty of the University of Virginia in Candidacy for the Degree of Master of Fine Arts

\section{Department of Drama}

\section{University of Virginia}

May, 2013

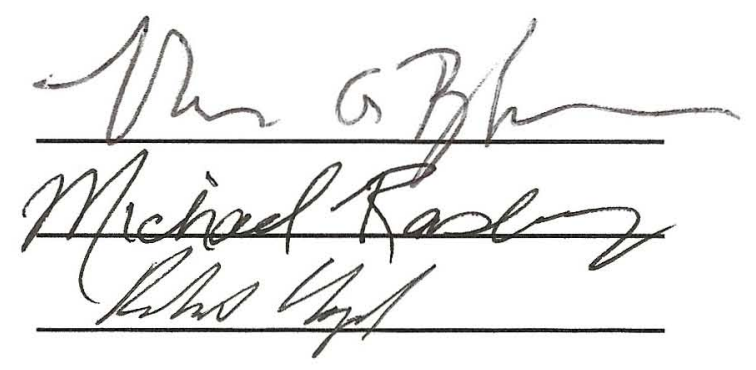




\section{Table of Contents}

Introduction

Chapter 1:

What is the purpose of the scenic design portfolio?

1

Chapter 2:

Types of Portfolios: Hard vs. Digital

8

Chapter 3:

Layout Options

16

Conclusion

24

Works Cited

25

Appendix 1:

Interview Questions

26

Appendix 2:

University graduate level portfolio

requirements for admission into scenic design

programs in the United States

Designers Consulted 


\section{Introduction}

I wrote this thesis with the intention of providing a comprehensive guide to developing a scenic design portfolio. As a graduating scenic design MFA student at University of Virginia, I developed a growing interest in portfolio development and website building. With little knowledge on how to easily construct a digital portfolio, or how to make it easier to maintain my hard portfolio, I contacted some scenic designers that had way more experience putting together an impressive portfolio. Each designer had their own techniques and preferences for portfolios, but I used their information to guide my own portfolio development in the right direction. The contents of this document should be thought of as a stepping-stone to building a portfolio that suits the designer and also help with the selection and arrangement of materials included in the portfolio. From my experience, a designer's portfolio is never finished and is constantly evolving to suit the needs of the designer's career development.

The portfolio displays the designer's work in a creative, well-defined and organized format. The portfolio serves two main purposes. First, the portfolio is an archive of the designer's work. Secondly it is an indicator of the designer's process, skill sets, techniques, collaborative skills, and resourcefulness when entering the job market. A resourceful designer anticipates what to prepare before the interview process, and models the portfolio to suit what the employer may be looking for.

To research the development of a scenic designer's portfolio, I interviewed seven designers currently working in the United States. During these interviews I asked the designers a series of questions (see Appendix 1). Each designer's response to the 
interview questions were used to guide my thought process and helped formulate conclusions about portfolio development.

In the following document I will reference my own and other designers' portfolios in order to clarify the topics discussed. I will examine the different types of portfolios, diagram different formats of organizing the body of work, consider website building options, and include examples of the evolution and growth of a designer's portfolio. 


\section{Chapter 1: What is the purpose of the scenic design portfolio?}

The portfolio is intended to display and organize a designer's body of work in a way that best represents who they are as a designer, how they work, and how to become more marketable. As with any interviewing process, the portfolio's purpose is to represent the work of the designer in a clear way that shows their range and capabilities that will appeal to theatrical companies. The pages of the portfolio include clear, highquality photographs that accurately showcase projects or a production, along with process documentation, models, draftings, and conceptual renderings. In Rafael Jaen's book, Showcase: developing, maintaining, and presenting a design tech portfolio for theatre and allied fields, Jaen includes a quote from Peter Beudert. Beudert, scenic design professor at University of Arizona, says, "You should include...the steps you took which reflect your thinking as well as your way of working" (Jaen 64). By including these steps and images, the designer demonstrates how the show evolved during the production process.

The portfolio should include images that display a designer's range. These include, but are not limited to musicals, dramas, comedies, opera, touring shows and children's theatre, along with installation art, museum displays and similar design projects. While all of these genres may not be in a designer's portfolio, some variety will help inform a future employer of the designer's versatility, and furthermore creates more opportunities for employment.

In order to showcase variety and versatility within the portfolio, find a medium that best displays these categories. For instance, Adam Koch, New York scenic designer, 
created a website which clearly displays over twenty photo galleries on his homepage ${ }^{1}$ using a website building program called Carbonmade. When Koch is interviewing for a job, he explains how he is able to "tailor [the website] to who is looking at it." He goes on to clarify, " So if I am designing a musical for somebody, I can hide all the plays from the website, so I know they are looking at what they want to see." [Koch, Adam]. Personal interview. [October 13, 2012]. In these cases Adam Koch is discussing a project with someone who has seen his work before, and he chooses to limit his selection of work to what will suit that job he is hoping to get. Therefore it is not a concern for him that some of his shows would be hidden from public viewing during that time. If the designer were trying to make new connections, it would be more beneficial to include a wider variety within the portfolio.

Because the portfolio is the designer's way for others to see their work in the most positive way, it is important to carefully decide what is included in the portfolio, and equally what should be omitted. A designer should carefully edit the portfolio and remove anything that does not best represent the designer's work. While speaking with Daniel Mueller, another New York based scenic designer, he explained that he has omitted certain items from his website for a few reasons. In some cases he omitted images because he felt he had too many images of one show. Mueller suggests that the designer not include images that ultimately give the same information. For example, when participating in a job contact service, such as the South Eastern Theatre Conference, time is limited for interviews. So it is more beneficial for the designer to show off their best work that shows their capabilities in the least amount of pages. A

\footnotetext{
${ }^{1}$ Adam Koch's web address: http://adamkoch.carbonmade.com/
} 
designer may also want to omit images that display a failed collaborative effort, or lack of communication amongst other designers involved in the process. In this case, the failed collaboration may be reflected in the production photographs. Mueller gives the following advice:

Don't belittle your own work. Never talk about horror stories. If it isn't good enough to show, then don't show it. Unless whatever you are saying is reassuring. [Instead one might say] we ran into a problem, and this is how we solved it. End with a positive. Some people think quantity is better, but it is really about the quality. [Mueller, Daniel]. Personal interview. [October 14, 2012].

There are other things to consider when choosing the photographs to include in the portfolio, such as dynamic compositions and photo resolution. Here are a few examples of images that are appropriate for the portfolio, and also those that should not be included when developing a portfolio.

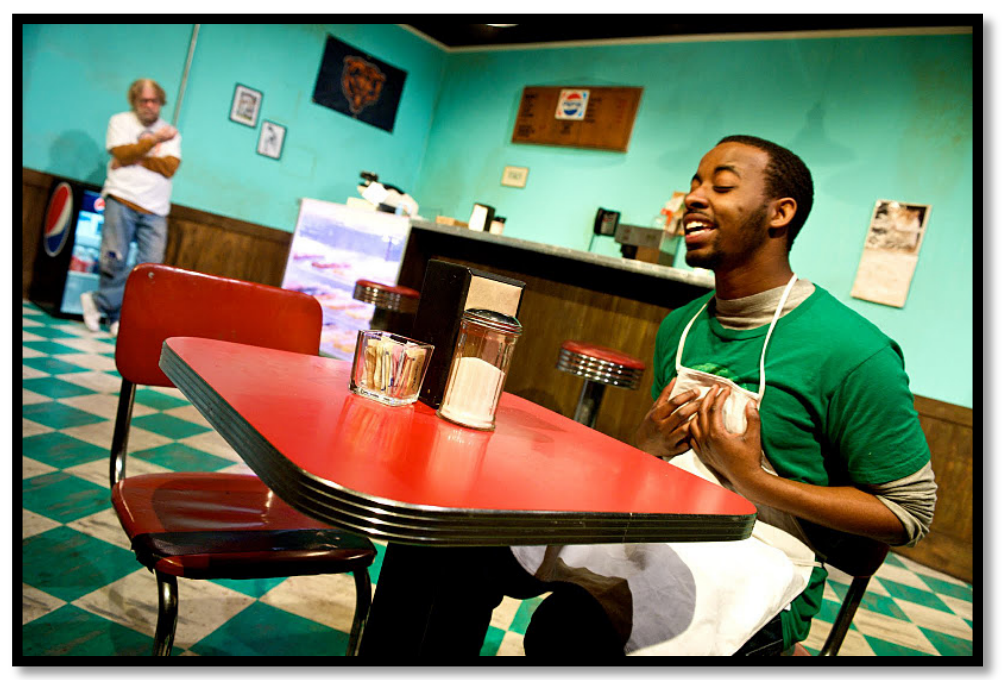

Superior Donuts. 2011; Live Arts Theatre. Charlottesville, VA. Scenic Design by Kathryn Springmann. Directed by Chris Baumer and Mendy St. Ours. 
Here we see an image from a production of Superior Donuts. While it is a nice photograph, it is not a good balance of actors to scenery. The image focuses too heavily on the actor in the picture and does not give a good sense of what was designed for the actors. This is more of a promotional photograph and not the best option when developing a scenic design portfolio. In addition to this photograph, the designer would also want to include the next image:

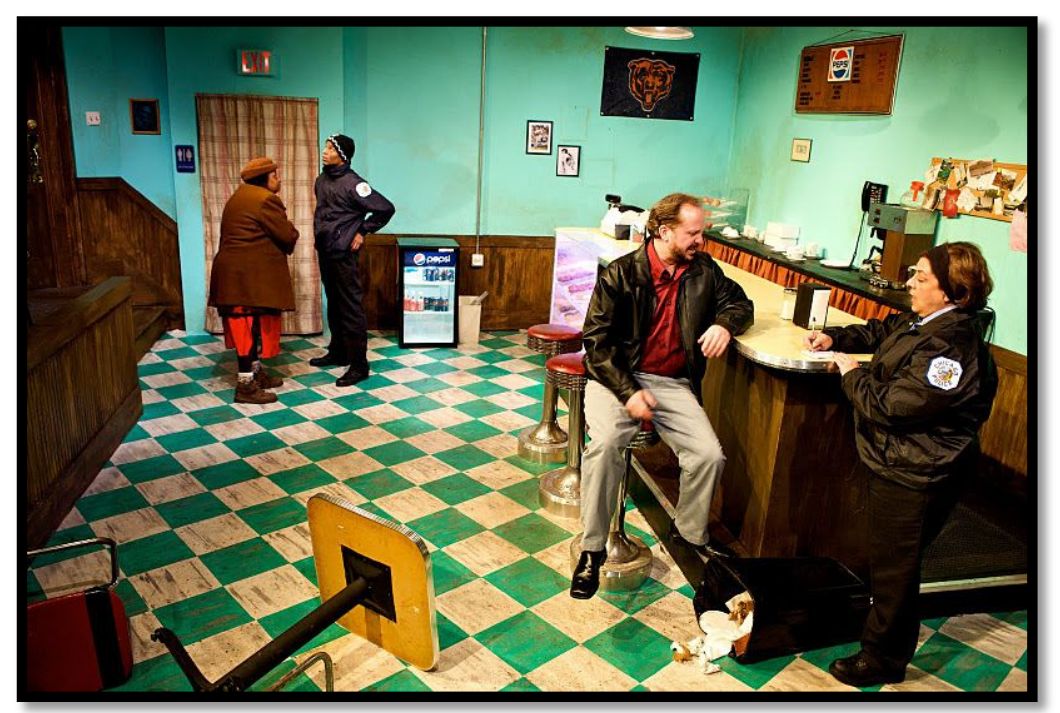

Superior Donuts. 2011; Live Arts Theatre.Charlottesville, VA. Scenic Design by Kathryn Springmann. Directed by Chris Baumer and Mendy St. Ours.

This is an image from the same production of Superior Donuts. This photograph shows the actors interacting with the space, but is not focused specifically on the actors. It gives a better sense of the space and design, and the image resolution is clear.

Sometimes a designer may realize that the composition and positioning of the photograph is crooked, out of focus, or unbalanced. If this is not a problem that can be easily fixed by cropping or editing the image, it may be best to discard the image from the portfolio altogether. The next pair of photographs demonstrate the importance of having clear, well-balanced images. 


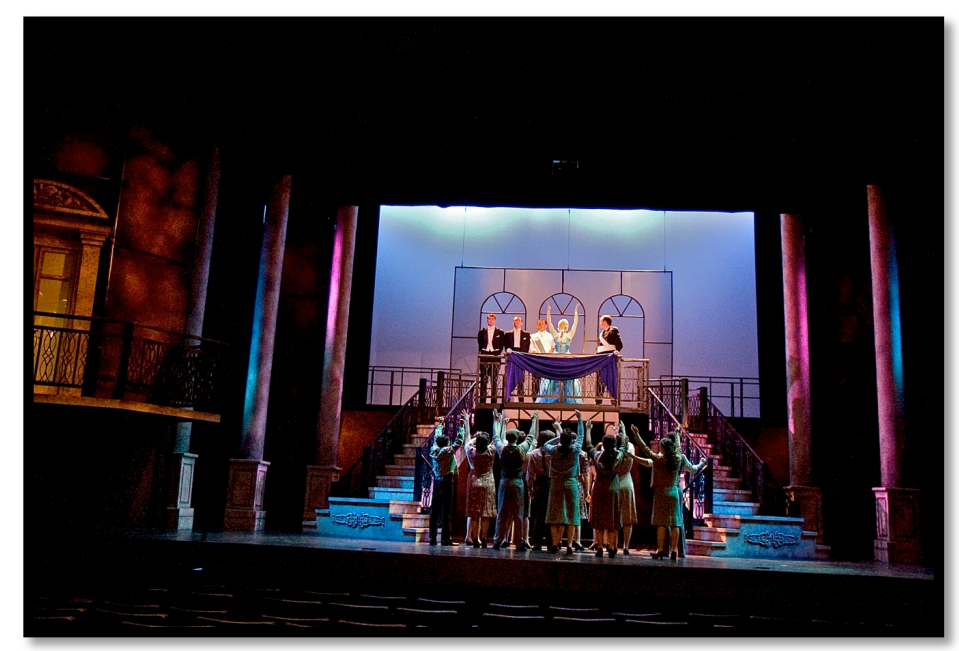

Evita. 2011; University of Virginia. Culbreth Theatre. Scenic design by Kathryn Springmann. Directed by Robert Chapel.

The image above has a few flaws. The composition of the image is not well balanced.

The image weighs heavily on the left side and the scenery on the left distracts from the action happening in the focus of the image. Also, the image is leaning to the right.

Whereas looking at this other image from the same production of Evita the resolution is much better.

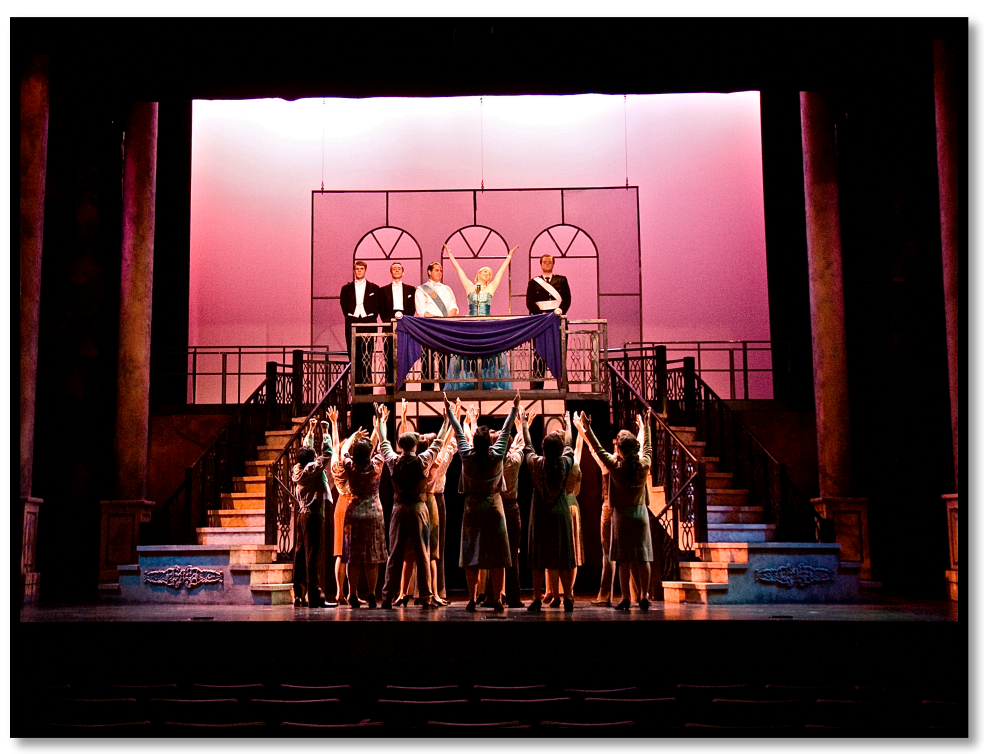

Evita. 2011, University of Virginia. Culbreth Theatre. Scenic Design by Kathryn E. Springmann. Directed by Robert Chapel. 
In the second image, the resolution is much better. The image is balanced, and with some editing, a crooked image may be adjusted. This would be a much better option to include in the portfolio.

In addition to the production photos, a designer should also include sketches and images of models in their portfolio. Todd Rosenthal, Tony award winning scenic designer and Associate Professor at Northwestern University, includes many images of set models and sketches on his website. As previously stated by Peter Beudert, these are meant to "reflect your thinking as well as your way of working"(Jaen 64). The next image shows of one of many models Rosenthal includes on his website.

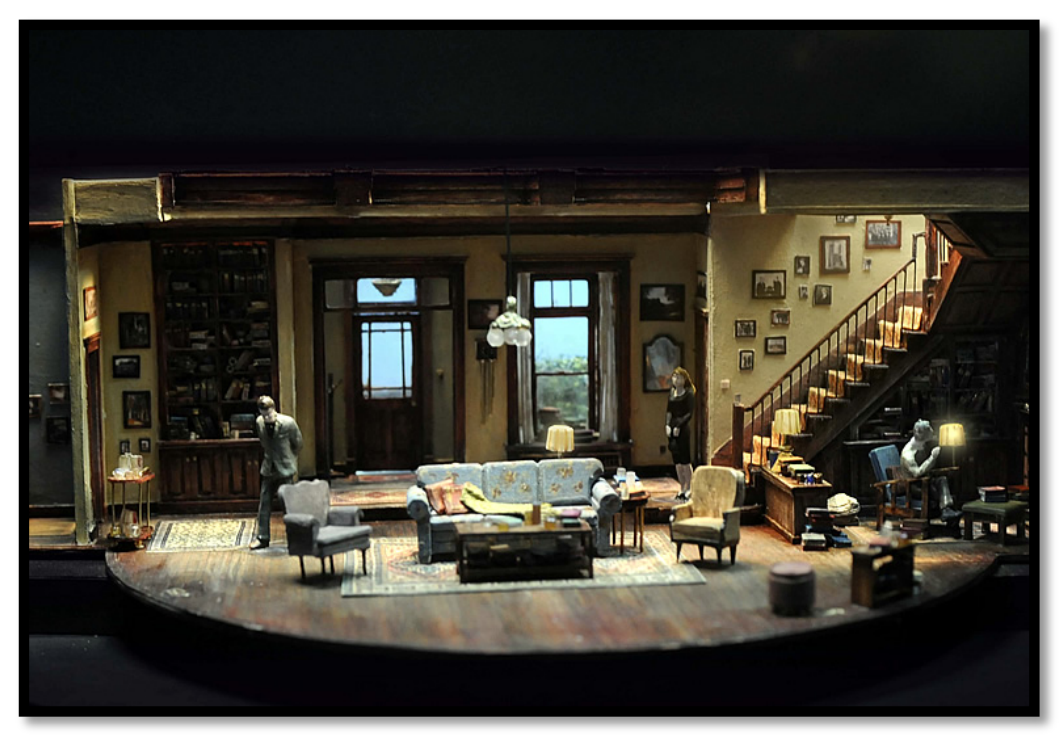

Who's Afraid of Virginia Woolf model. Steppenwolf Theater. Chicago, IL. Directed by Pam Mackinnon and Scenic design by Todd Rosenthal. Photograph used with permission by Todd Rosenthal.

As seen above, the image shows a photograph of one of Todd Rosenthal's models that he includes on his website. Along with this, he has many other models and also some early design sketches. 


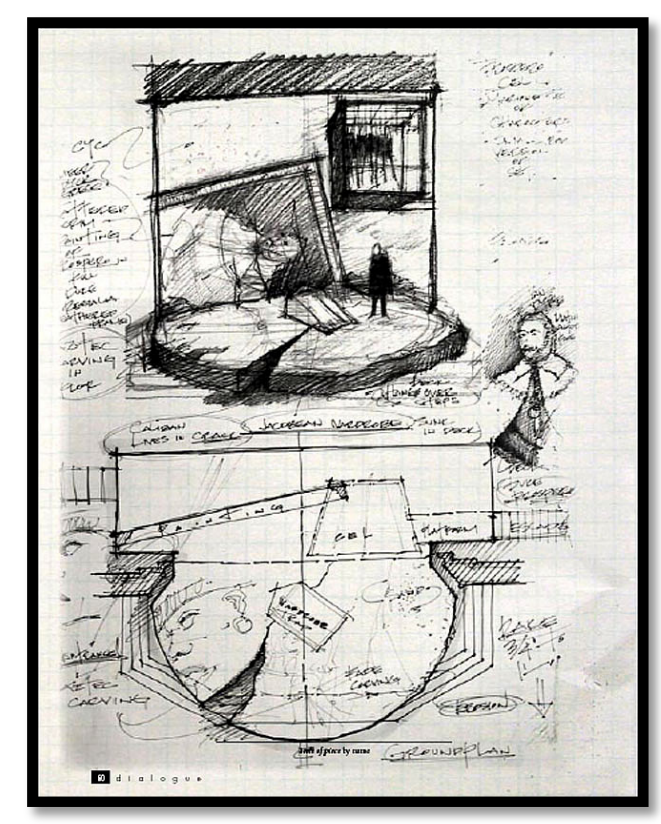

Here is a concept sketch from The Tempest by permission of Todd Rosenthal.

The selection process is very important in portfolio development, displaying that which shows how the designer works, and what a designer can achieve. Whether designers present their work in a digital format or in bound portfolio, image selection and composition remain equally important in the process.

In the next section, I will discuss the difference between a scenic designer's hard portfolio versus a digital portfolio. A hard portfolio is a collection of photographs, conceptual drawings, draftings, and other works of the designer that have been arranged and mounted onto a page. This portfolio is sometimes bound or assembled as a pack of loose leaves. The hard portfolio gives a future employer the opportunity to look closely at the designer's work. The other type of portfolio is categorized as a digital portfolio. In this format, the designer has organized their body of work on a website, or in some digital format that may be shown via a laptop, iPad, or possibly through email. A digital portfolio takes the portfolio out of the employers hands and presents the information in a different way, being that of a computer screen. 


\section{Chapter 2: Types of Portfolios: Hard Portfolios vs. Digital Portfolios}

Within the last year I interviewed several scenic designers currently working in the United States. In these interviews we discussed the purpose of the hard or digital portfolio in the interview process. We discussed preferences on layouts, the practicality of the portfolio, cost, and the updatability of their portfolios. Richard M. Block, interim department head of drama at Carnegie Mellon University, gave some sound advice on the issue of hard portfolios versus digital. He says, "My overall feeling is that any designer should show [his or] her work in whatever way makes [him or] her most comfortable. That is a general start. There is nothing worse that trying to show your work in some manner that is awkward. It will make you feel awkward as well and you will not show as best you can." He went on to say, "The way in which a portfolio is shown has as much to do with your audience as anything else". [Block, Richard]. Email interview. [November 1, 2012]. That being said, it is important for the designer to research the company before the interview, and try to determine which way they may prefer to view the material. But more importantly, the designer must decide which medium works best for the development of their portfolio.

\section{Hard Portfolios}

While interviewing the designers about this topic, we first discussed the function of a hard portfolio. Typically, when one is in an educational setting, a hard portfolio is necessary for admission in the program, and examined during portfolio reviews at the end of each term. See Appendix 2 for the admission requirements of a few MFA scenic design programs in the United States. 
Though hard portfolios seem to be more suited to the more traditional employers, it is difficult to maintain a hard portfolio. This is not to say that a hard portfolio is not useful or still appropriate. Todd Rosenthal speaks positively of the hard portfolio format. In our interview he explained,

"The big advantage ... of a hard portfolio is the ease in which you can access images during an interview. You can also leave out an image that an interviewer particularly likes [for further discussion]. I require a hard portfolio for applicants for graduate school. I like to see real drawings and large photographs. I am better able to see an artist's hand in an actual portfolio. I am not talking about the cases with the annoying plastic sheet covers. I prefer images that are mounted on separate pieces of board." [Rosenthal, Todd]. Email interview. [October 30, 2012].

However, maintaining a hard portfolio becomes more difficult when trying to change the layout of the portfolio. This usually requires reprinting images. This can become quite costly over time. However, if it is required to have a hard portfolio, it is recommended to keep multiple copies of the images used in the portfolio on a separate storage device that allows the designer to quickly access the photographs he or she would like to use. Another option is to create portfolio pages in a program, such as Photoshop, and print off new pages as you update the portfolio. These portfolio pages may be stored on an external hard drive to ensure that they are not lost.

In separate interviews with Adam Koch, Mikiko Suzuki Macadams, Todd Rosenthal, and J. Patrick Adair, each of them said that they prefer having loose pages for their hard portfolios. This way the designer can take only the appropriate pages for the 
interview. J. Patrick Adair, Los Angeles-based scenic designer, explains that having a hard portfolio is a safety feature. J. Patrick Adair went on to say, "By having the pages with the designer, one does not have to worry about a power outage or a bad Internet connection that may prevent the designer from showing a digital portfolio. The designer will also know that the colors are right in the photograph, because colors may appear differently on different computer screens." [Adair, J. Patrick]. Email interview.

[November 9, 2012]. These individual portfolio pages are a simple, easy way to showcase the work of the designer.

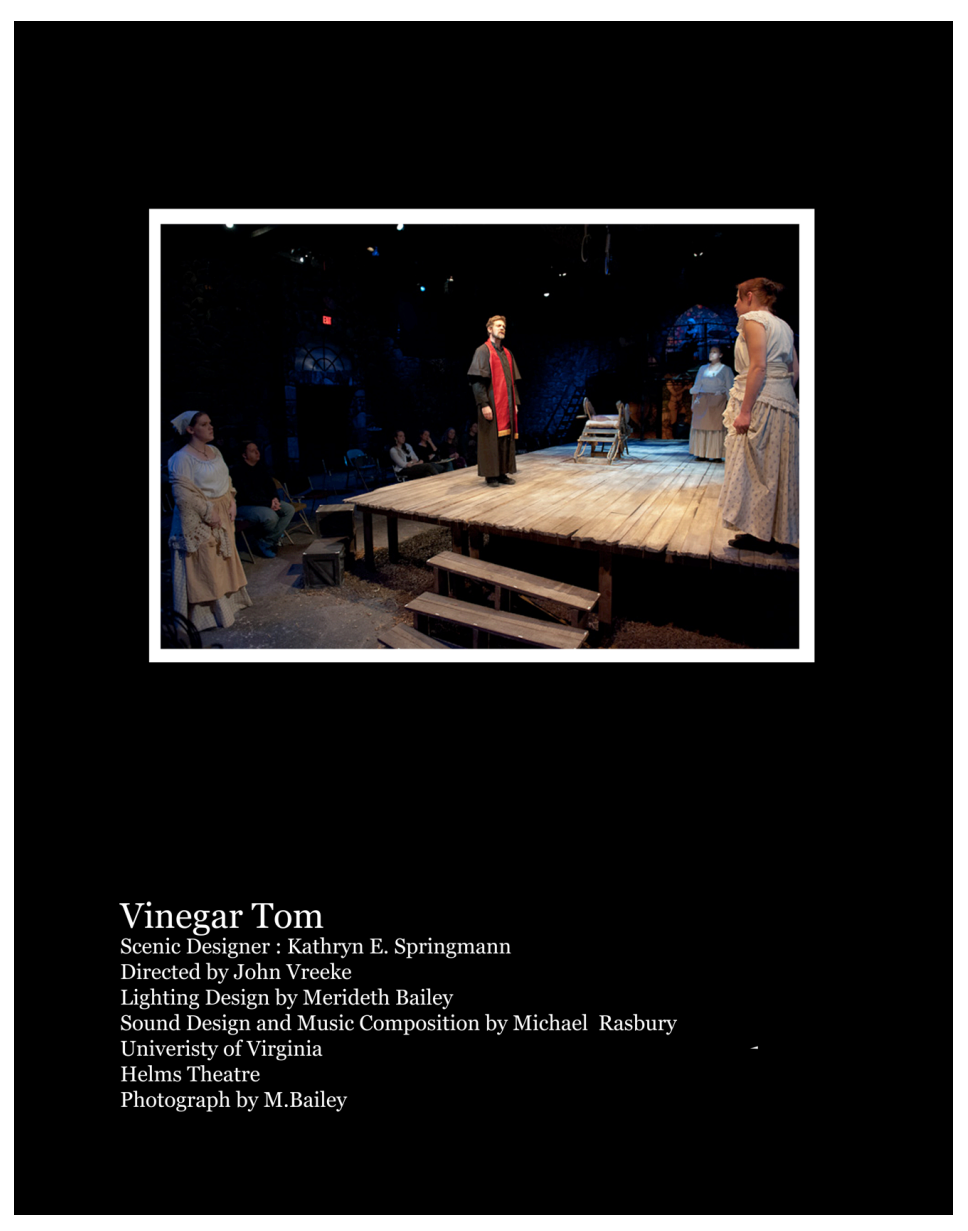

Example image of a portfolio page created in Photoshop. Photograph mounted to black board with the image information printed clearly on the bottom of the page. 
When displaying the images, make sure to include all of the necessary information about image. This information should include:

1. Title of Show

2. Production Team
a. Your Position, aka, Scenic Designer
b. Director
c. Choreographer (if applicable)
d. Lighting Designer
e. Sound Designer

3. Photographer (if you did not take the photograph)

It is important to include all of the appropriate credits to the production team. The person interviewing the designer may have previously worked with one or more of the people on the production team. If they are familiar with their work, it may help a scenic designer to get the job. Also, it is just a courtesy to emphasize that the designer is not trying to take credit for elements of the show in which they did not design.

It should be made clear that there are positives and negatives to having either kind of portfolio. Todd Rosenthal has a preference for the hard portfolio format, and he explains why this is his preference. Here is what he had to say about the subject: "Sitting down with a director and showing images on an iPad is probably fine. It shows the work, but I believe we are losing the battle of handcraft vs. computer-generated stuff. And, that is a shame. But, I know it is a bit impractical, and very expensive to generate and carry around a portfolio. A digital website is imperative for any designer. My website has led to many design jobs."[Rosenthal, Todd]. Email interview. [October 30, 2012]. 
In the next section I will discuss the digital portfolio, and the benefits and complications that may come with a portfolio in this format.

\section{Digital Portfolios}

In the past few years, digital portfolios have become a necessity for scenic designers. The practicality of a digital portfolio is what makes them so appealing. Updating a portfolio is time consuming, and sometimes that is time a designer does not have. Creating a digital portfolio provides the designer with a simpler and more efficient way to develop, maintain, and update the portfolio.

When interviewing for a position, and it is impractical to conduct a personal interview, having a digital portfolio allows the applicant to send the information quickly. It prevents the designer from having to print off another copy of the portfolio and send it through the mail. There are some variables that should be considered when creating a digital portfolio. As mentioned in the previous section, the colors of the images may appear differently on another person's computer screen than on the designer's screen. If the designer is presenting the digital portfolio at the interview, the designer should consider bringing his or her own computer or iPad. Daniel Mueller prefers an iPad because it receives Internet access in any location. Another thing to consider is the screen size. Some digital portfolio pages may appear out of proportion on another computer screen. By providing the display device, a designer can easily manage this. Just be aware that if a portfolio is being sent via email, all of these potential issues become problematic.

A popular type of digital portfolio includes the website. The website creates the most accessible form of digital portfolio. For some, the idea of creating a website may 
seem daunting at first. But after asking other designers, I discovered some computer programs that make it quick, easy and user-friendly for designers creating their website.

Some programs used by the designers interviewed for this thesis include iWeb, Carbonmade, and Big Black Bag. These website-building programs each have click and drag features. This allows the user to select images from their image files and drag the picture files directly onto a web page template. Here are examples of web pages created from each of these programs.

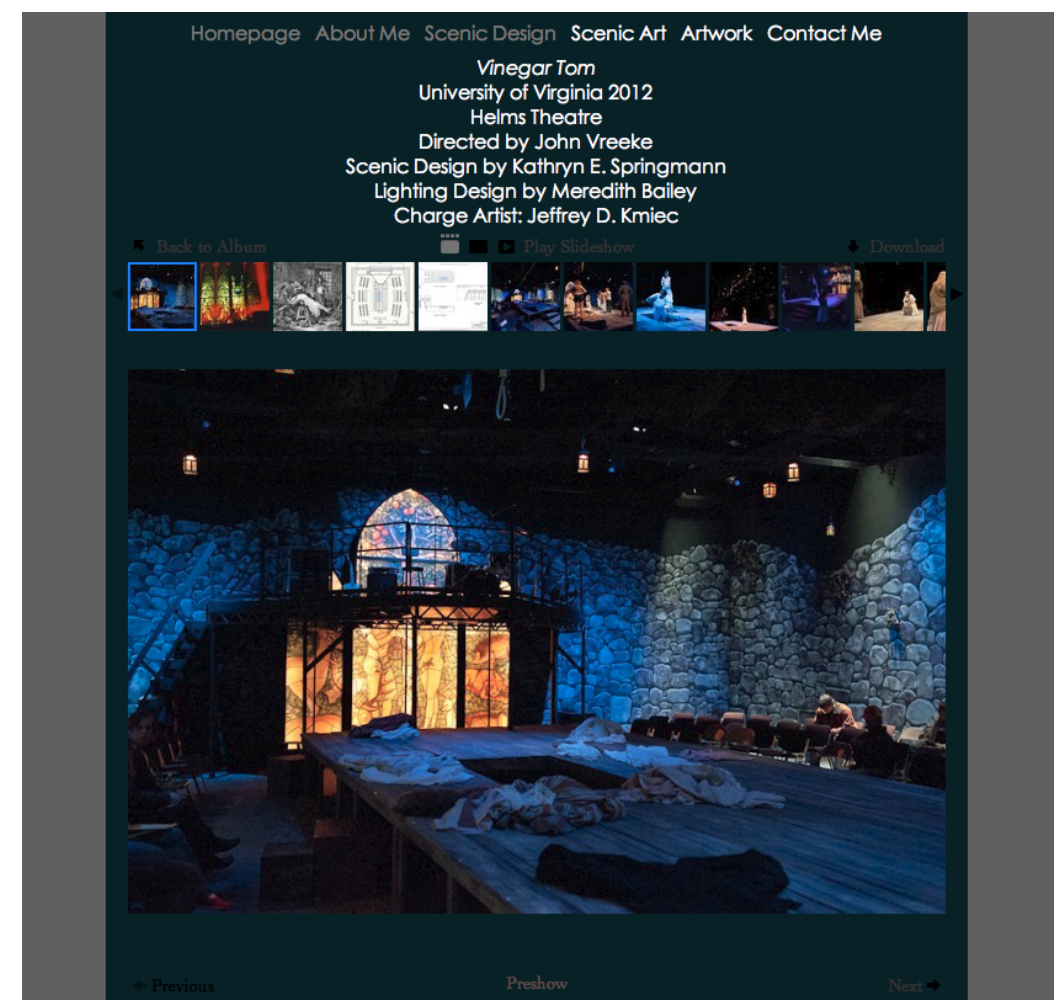

Web page made using iWeb. kathrynspringmanndesign.com. Scenic design: Vinegar Tom gallery. 


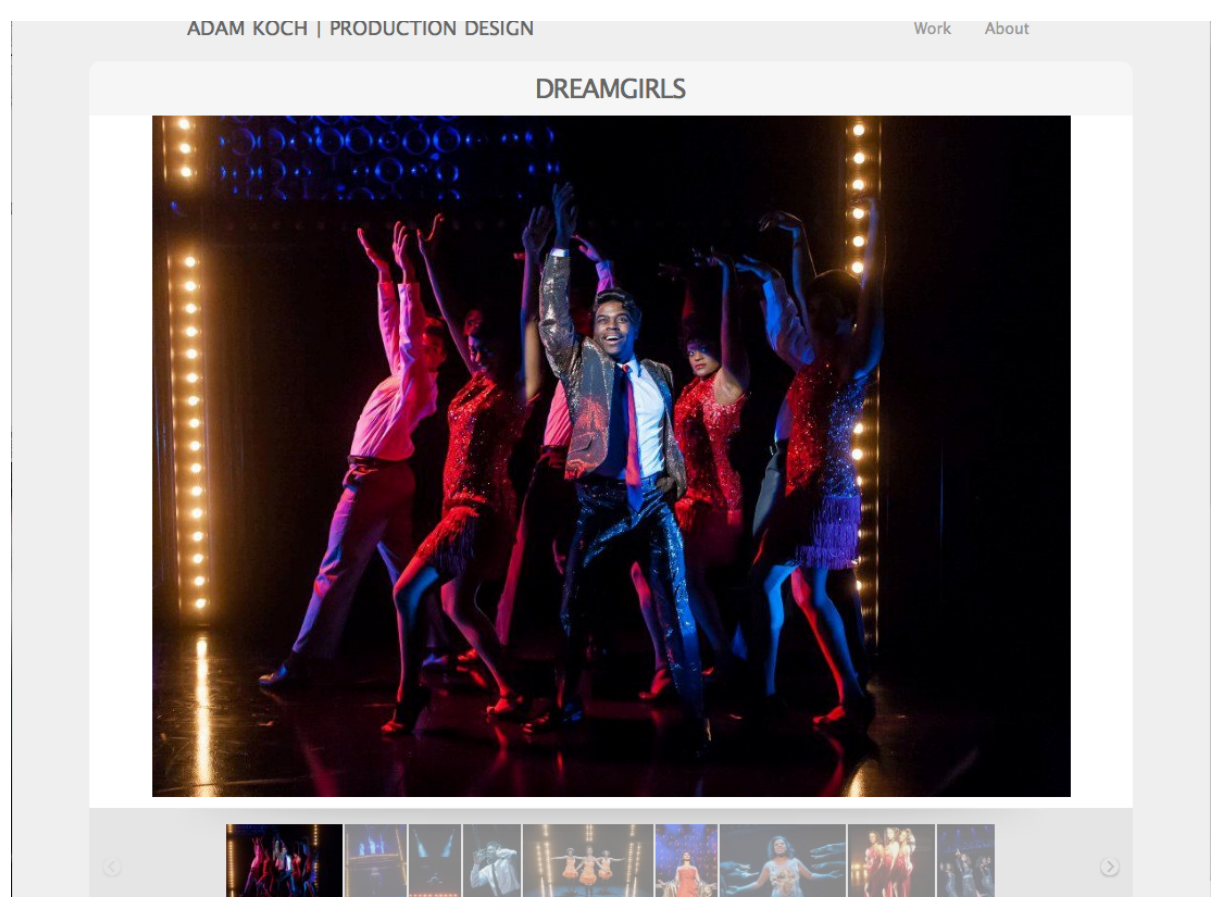

Web page created using Carbonmade. adamkoch.carbonmade.com.

Production Design: Dreamgirls gallery. Photograph used by permission of Adam Koch.

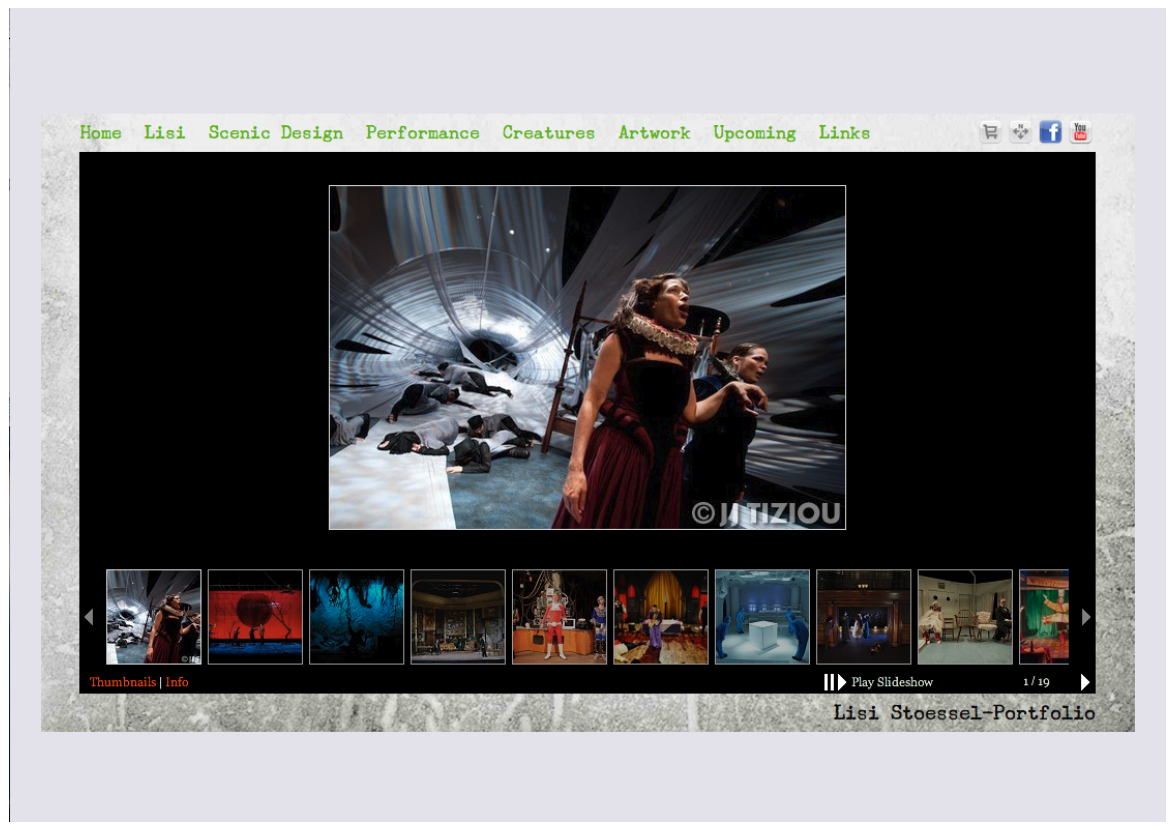

Web page created using Big Black Bag. www.lstoessel.com.

Scenic Design: Highlights gallery. Photograph used by permission of Lisi Stoessel. 
As seen in the previous images, each website provides a different presentation style. Each an easy solution to creating a website quickly. Once a designer is familiarized with these programs, it is possible to create a personalized website that displays the designer's individual aesthetic.

After discussing both format options, designers should find a way to develop both a hard portfolio and a digital portfolio format that works for them. Both have their own respectable place in theatre. 


\section{Chapter 3: Layout Options}

Whether a designer is working with a hard portfolio or a digital portfolio, the layout depends on the preferences of the designer. This section discusses organizing the portfolio, layout options, and presentation. When creating a portfolio, decide what the opening page will look like. This is the first thing anyone will see when looking at the portfolio. This first page may simply be a resume page, or an identification page for the designer. The opening page should be simple and direct. The introductory page sets the viewer up for what they can expect for the rest of the presentation.

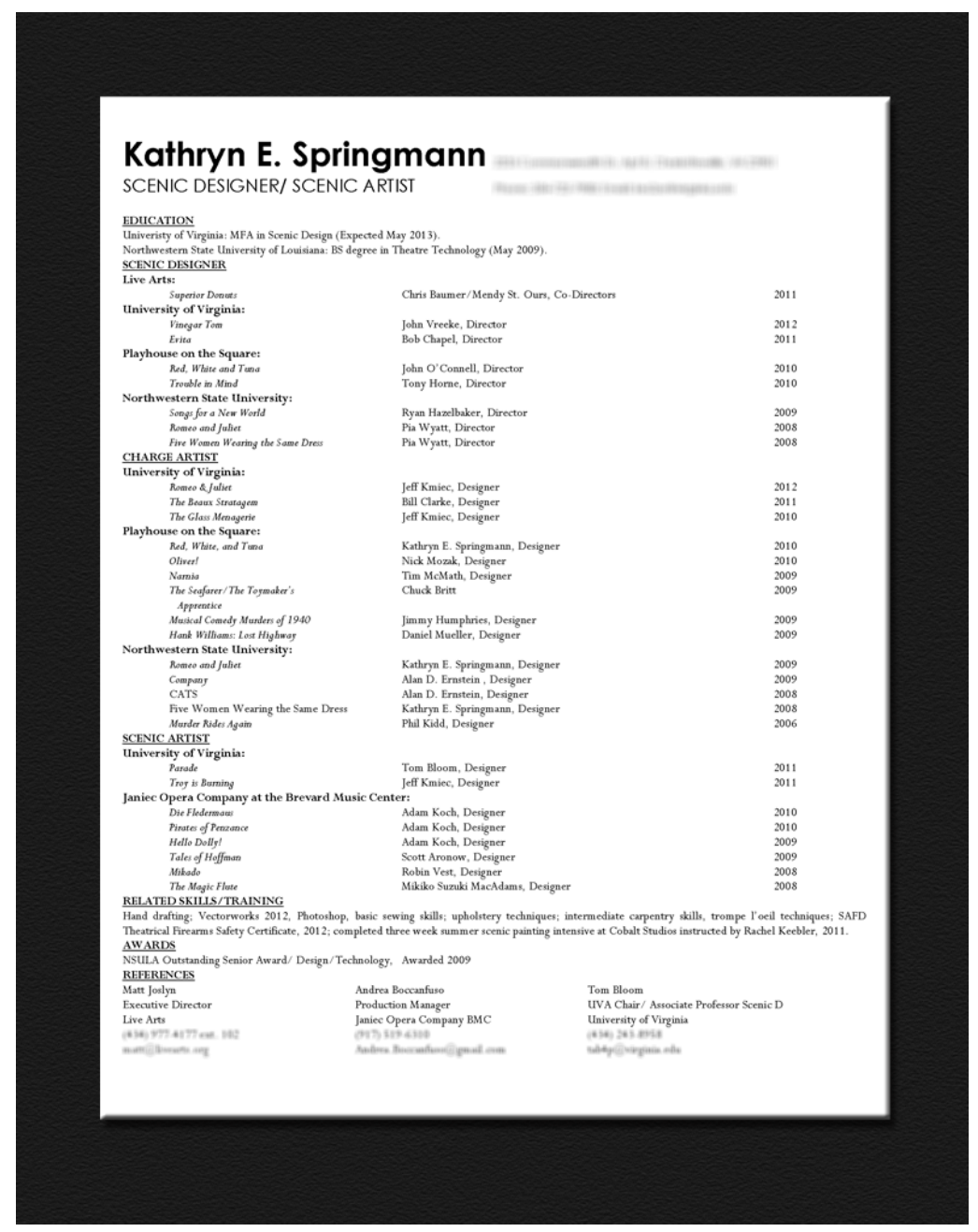

A sample of an introductory page. 
On a website, the designer's first page should be eye-catching. This introductory image should make the viewer want to explore the website further. When viewing a website, it is usually the case that the interviewer may not be viewing the site with the designer. On a separate page, the designer could include a photograph of themselves on the website. This way, the interviewer may associate a face with the designer's name.

Having a photograph of the designer on the website makes the designer more memorable in the employer's mind.

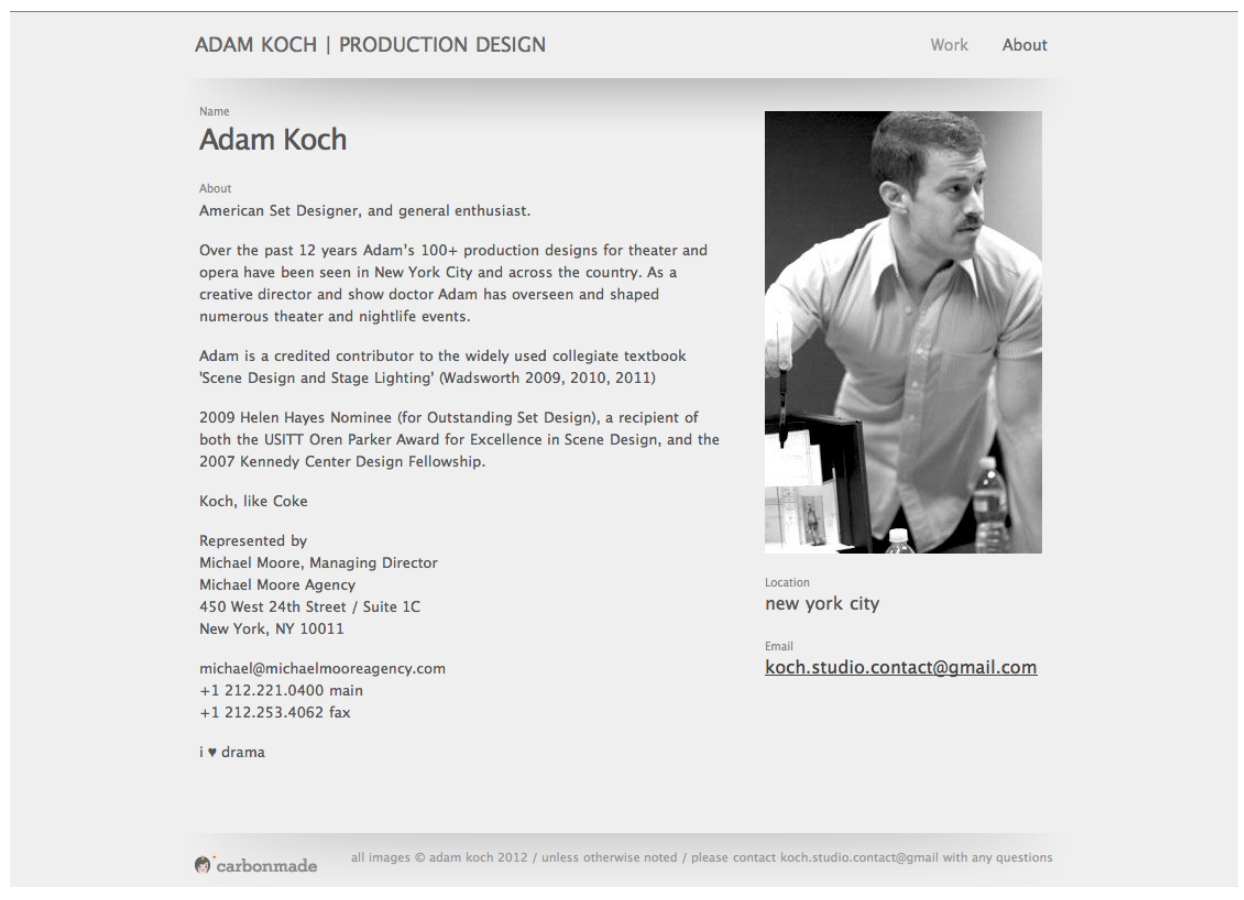

An "About" page on Adam Koch's website. He includes a brief bio about himself, and he includes a picture. Photograph used by permission of Adam Koch. 
When organizing the body of work in the portfolio, showcase the projects in the most logical and engaging sequence. Make sure to consider the positive and negative spaces on the page. Horizontal or vertical orientation is important to consider when presenting an image. Rafael Jaen discusses this in his book Showcase: developing, maintaining, and presenting a design-tech portfolio for theatre and allied fields. I agree with his statements about this layout planning process, and how the designer must choose the orientation and stick with it for the consistency of the presentation.

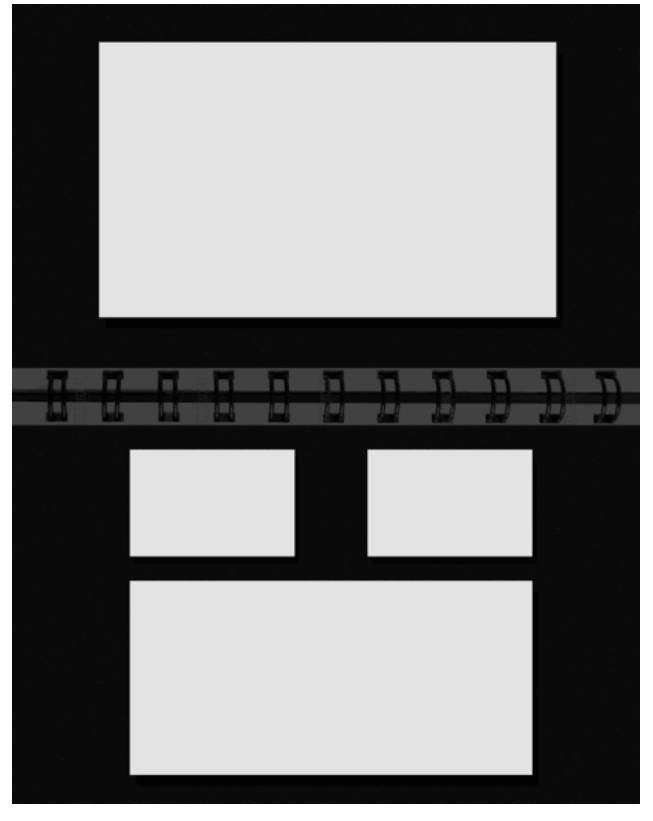

Vertical Layout

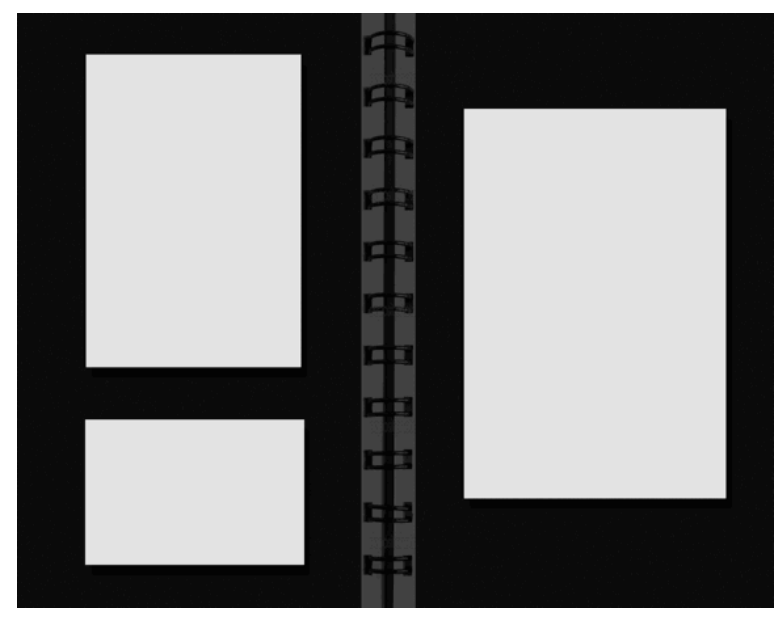

Horizontal Layout

Note how the images are arranged on the page in a way that fills the page, and considers the negative space on the page. The negative space signifies the space surrounding the images on the page.

The next thing to consider is how the designer should organize the body of work in terms of order in the presentation process. Most of the designers interviewed said to lead with the most recent project, and work back from there. 
As far as presentation goes, my hard portfolio transformed immensely over the last few years. I used to believe that because I am a painterly designer, my portfolio should be colorful and flashy. I included an assortment of eye-catching papers to back my photographs. Not only did this become time consuming, but also I felt it drew the focus away from the content in the photographs. The quality of the work should speak for itself. Mikiko Suzuki Macadams made it clear when she said, “Don't try to make it pretty. Be simple!" [Macadams, Mikiko Suzuki]. Email interview. [October 23, 2012]. There is no reason to clutter up the page with unnecessary pieces. The next two images demonstrate the difference between a cluttered portfolio page and a simpler option.

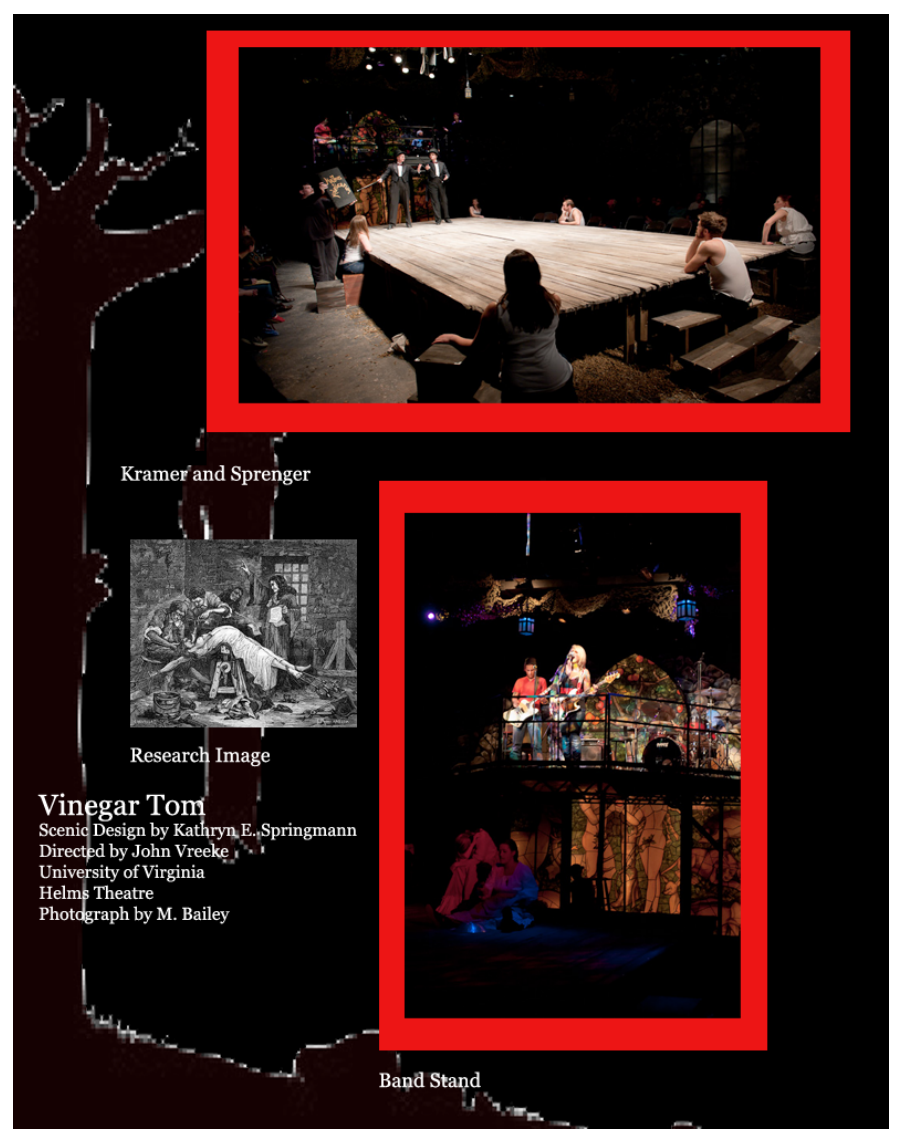

Mock portfolio page for University of Virginia's 2012 production of Vinegar Tom. Helm's Theatre. Directed by John Vreeke. Scenic Design by Kathryn E. Springmann. 
Here the page is cluttered with too much information and imagery. The focus of the page is in too many places. Also, the borders around the images distract from the images themselves. Instead of having all this on one page, the designer could break it up into two pages. Also, the captions are superfluous. These captions are things the designer could explain to an interviewer if asked about them.

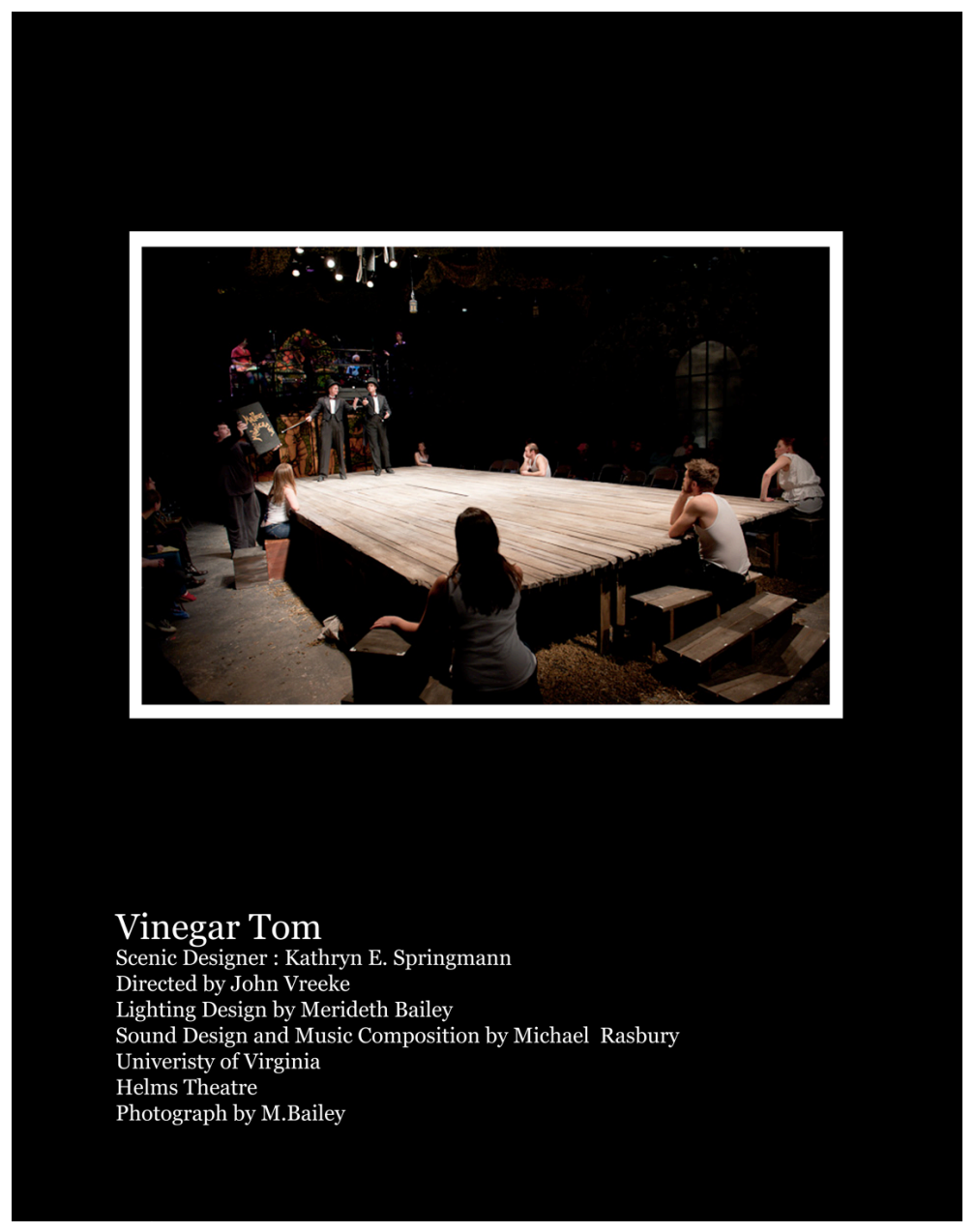

Here we see a much cleaner way of presenting the image. The eye knows exactly where to go. The negative space has been used efficiently, and only the necessary information is being given. This also allows for the designer to print a larger image for the page so that the interviewer can see more details in the work. 
Lastly, when choosing the images, make sure the interviewer gets a sense of the scale of the set. This is achieved by making sure to include pictures with the actors in them. By doing so, the viewer is able to understand the size of the space. Blank stage shots may be very misleading. Here is an example seen below:

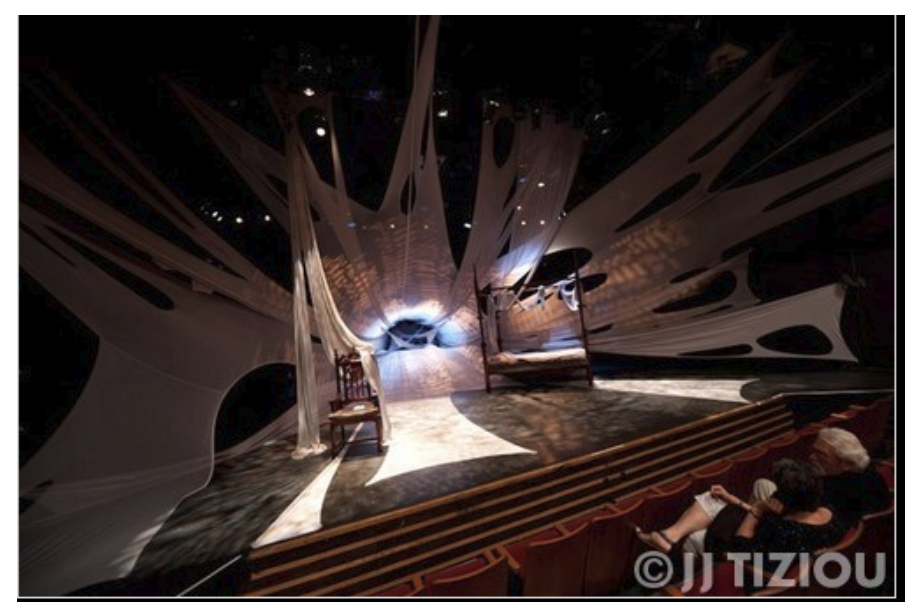

These images were taken from Lisi Stoessel's website by permission of Lisi Stoessel. These are production photos from Swim Pony Performing Arts' Lady M at Arts Bank 2011. Scenic Design by Lisi Stoessel. Directed by Adrienne Mackey. Lighting Design by Maria Shaplin. Costume Design by Alisa Kleckner. Photograph taken by J.J. Tiziou.

Here, the set looks quite large, and while the chair in the room helps clarify the scale, it is still a bit unclear.

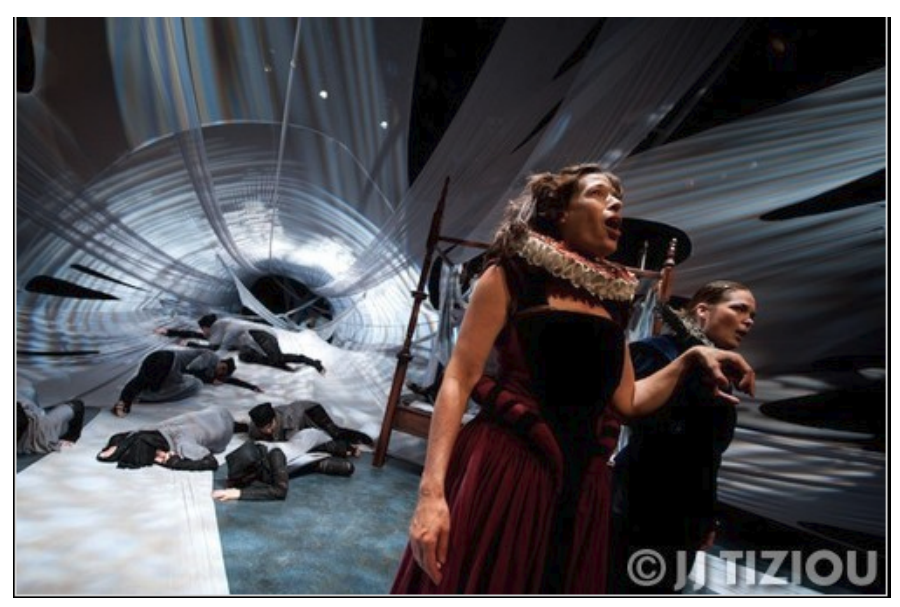

This image now includes the actors in the space. The space now appears smaller than it appeared in the previous image because the actors provide a scale reference. 
When speaking with Daniel Mueller about choosing images that include actors, he informed me that he stopped including full stage shots all together. In the case of Superior Donuts, when I chose discussed the second image that included more of the set, it was because it was about the balance of actor to set. The designer should include images of actors using the set, and not pictures that just emphasize the actor. Mueller explained that the images of the design should include how the actors relate with the set. The director wants the actors to use and interact with the set, not just act in front of it. By showing the way the actors interacted with the scenic designer's design, it allows others to see how well the designer collaborates with the artistic team. See the following images for an example.

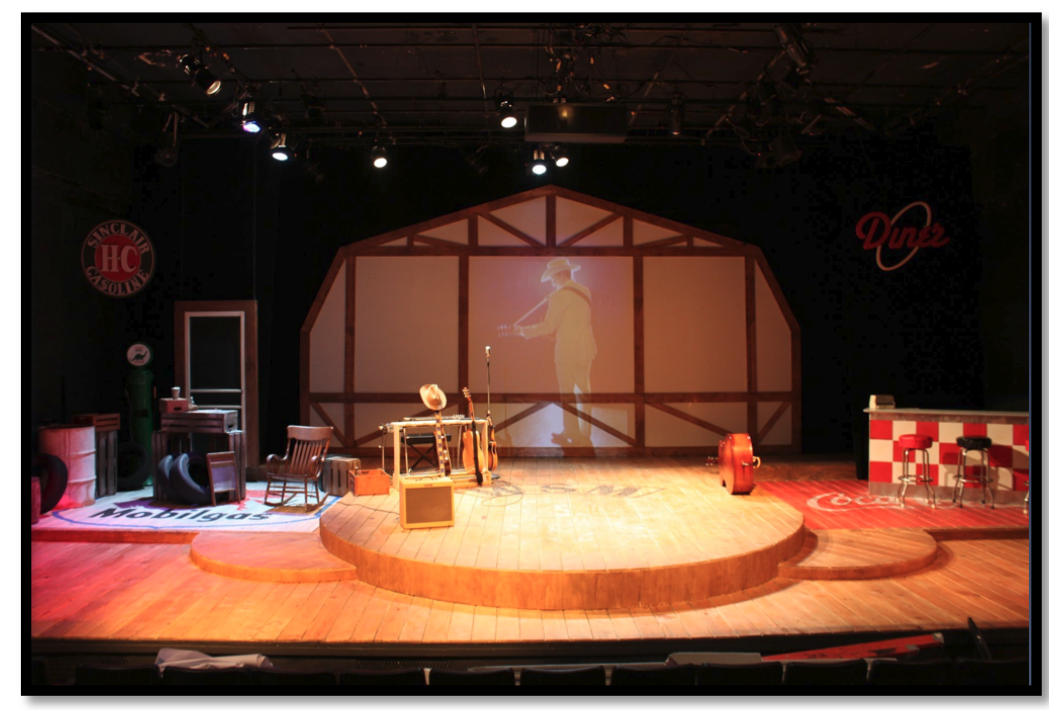

The next two images were taken from Daniel Mueller's website danielmuellerdesign.com by permission of Daniel Mueller. These are production photos from Playhouse on the Square's Hank Williams: Lost Highway at the Circuit Playhouse in Memphis, TN. Scenic and Projection Design by Daniel Mueller. Directed by Emily Wells. Lighting Design by Wes Calkin.

The above image is a full stage shot of Hank Williams: Lost Highway. Look at the following image, and notice how incorporating the actors better demonstrates how the set was utilized by the actors. 


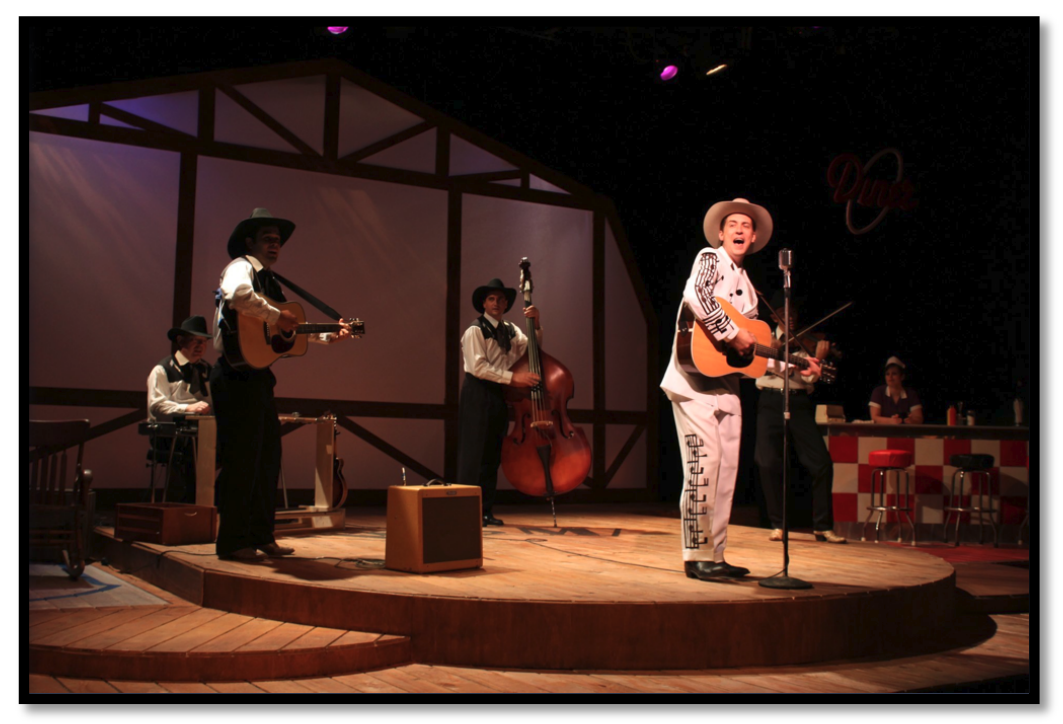

In this photograph of Hank Williams: Lost Highway, it is now clear how the actors used this space. It is more evident that the stage had isolated areas that distinguished different locations in the musical.

When determining the layout of the portfolio, these interviews led to the conclusion that less is more. Designers can say so much with a single image. Choose images that say the most about a design without becoming redundant. Also, choose high quality photographs that show the design in the best possible way. High resolution images look much more professional in a portfolio, so the designer should invest in a good camera for these process and production photographs. Show the interviewer how the design facilitated the director's vision, and try not to clutter the page with superfluous details that will only distract from the presentation. 


\section{Conclusion}

As a scenic designer, I wanted to create a guide that would answer questions about the process of developing a scenic design portfolio that could make me a more marketable designer. Throughout the interview process, I began to realize that the hard portfolio might soon be outdated due to its difficulty to maintain and the cost of maintaining a hard portfolio. As people become more comfortable with technology, it seems that keeping a digital portfolio may be all that is necessary. While this idea may not be accepted amongst all employers, possibly within the next decade we may see a change in portfolio development. However, as of now, it seems wise to keep a hard portfolio option available.

For someone currently applying for jobs, it is my experience that most companies, with the exception of most universities, are asking for a digital copy of the portfolio. Designers should spend time researching different programs and templates that are capable of creating a website or portfolio suited for the individual designer. I believe that by adapting to the digital world, designers demonstrate their resourcefulness and ability to keep up with the changing technologies developing in theatre. 


\section{Works Cited}

Jaen, Rafael . Show Case: Developing, Maintaining, and Presenting a Design Tech

Portfolio for the Theatre and Allied Fields. 2nd ed. Waltham, MA: Elsevier Inc., 2012.

Adair, J. Patrick. (2012, November 9). Email interview.

Block, Richard. (2012, November 10). Email interview.

Koch, Adam. (2012, October 13). Personal interview.

Macadams, Mikiko Suzuki. (2012, October 23). Email interview.

Mueller, Daniel. (2012, October 14). Personal interview.

Rosenthal, Todd. (2012, October 30). Email interview.

Stoessel, Lisi. (2012, November 4). Phone interview. 


\section{Appendix 1}

\section{Interview Questions}

- What do you feel is the purpose of a design portfolio?

- How do you choose your images?

- How has your portfolio changed/evolved over the years?

- Do you have a hard portfolio? If so, what do you feel is the purpose of having a hard portfolio as opposed to or in addition to a digital portfolio? What are the benefits? Do you feel like a hard portfolio is still worth maintaining compared to a digital portfolio?

- If you have a digital portfolio, what program did you use to create it? Is it easy to update/maintain using that program? How often do you update it?

- What information do you find most important to include in your portfolio? Whom should you credit on the portfolio page, and how much information needs to be listed with the photographs?

- How did you organize your body of work? How did you choose to start with one show, and with what show do you like to end?

- Everyone has their portfolio development "don'ts" What would you say are your portfolio don'ts? 


\section{Appendix 2}

\section{University graduate level portfolio requirements for admission into scenic design programs in the United States}

\section{Northwestern University:}

A sample portfolio of photographs or scanned images on CDs of design work (production photos, renderings, etc). Other artistic skills (drawings, renderings, photography, sculpture) that do not need to be returned. Applicants interviewed at U/RTA do not need to send a sample portfolio.

\section{Carnegie Mellon:}

Evidence of your design process which could include preliminary sketches, research, rough models, sketch-up work, etc. Color sketches and/or models of your design work. Production shots of your design work, performance art, installation work, etc. Ground plans, drafting, and detail drawings (hand or computer-generated). Examples of supporting skills in your area of interest (which might include prop work, scenic art) or in a secondary interest such as drawing, painting, photography, ceramics, sculpture, etc.

\section{Yale University:}

No CDs, slides, or videos are accepted as part of a set design applicant's portfolio. All such materials are returned, unreviewed, to the applicant. A portfolio should only be mailed to the Design Department if the set design applicant cannot schedule an in-person interview in New Haven. Every piece in the portfolio must be marked with the applicant's name, the name of the play, the date of creation, and whether it was realized in production. If the portfolio needs to be returned, a $\$ 20$ handling fee must be included in the portfolio to cover the return shipping unless the applicant retrieves it in person. 
Portfolios are returned after the review process is completed. The portfolio is not an advertisement and should not be "dressed up" to "sell" oneself. Please avoid large mats, acetate covers, superfluous graphics, and other forms of "eyewash." Such dressing does not make up for weak drawing and design.

\section{Boston University:}

The sample portfolio should feature one designed show organized into a designer's package. This should include, but not be limited to: research (visual, sociologic, historic); abstract response; production concept; scene breakdown; sketches; renderings; painters elevations; drafting; any paperwork generated during the design and production process; and photos of models. Applicants should also include photos of the finished production.

\section{California Institute of the Arts:}

Prospective students applying to the Programs in Design and Production (scenic, costume, lighting, video, sound, and technical direction) must bring or submit portfolio materials to our online portfolio site, and bring portfolio materials to an in-person interview. Students who are unable to attend an in-person interview may schedule a phone or video interview. Examples of production work and design, as well as drawings. Pieces that demonstrate photographic and/or graphic skill. Fine art work, sculptures, models, or photographic documentation of the aforementioned. Documentation of fully realized original work through video, photographs, scripts, and storyboards, as well as documentation of works-in-progress. Architectural drawings, textile work, performance art, video work, poetry, and creative writing samples are also welcome. 


\section{Designers Consulted}

J. Patrick Adair, an art director for television. Some of his recent projects are "Jim Rome" on Showtime, "The Late Late Show" with Craig Ferguson, and "The Next Food Network Star". He received his master of fine arts in Scene Design from CarnegieMellon.

Richard Block (rblock@andrew.cmu.edu) has been on the faculty at Carnegie Mellon for twenty-five years, including eleven years as Associate Head of the School (including a stint as Interim Head), following a freelance career based in New York City. Dick has been active as a scenic designer having created work seen at Virginia Stage, the McCarter, Pittsburgh Opera Theatre, The Human Race, the Pittsburgh Public Theatre and the Shakespeare Theatre of New Jersey. Dick is co-author of Scene Design and Stage Lighting (10th edition to be published soon). Dick has been active with USITT and has participated with KC/ACTF since he began teaching, having served as Design Chair of Region II, Festival and Design Respondent in a number of regions and as the first National Design Chair. He is the recipient of the Kennedy Center Medallion for Distinguished Service. Dick received his MFA from Northwestern University and is a member of USAA.

Adam Koch American Set Designer, and general enthusiast. Over the past 12 years Adam's 100+ production designs for theater and opera have been seen in New York City and across the country. As a creative director and show doctor Adam has overseen and shaped numerous theater and nightlife events. Adam is a credited contributor to the widely used collegiate textbook 'Scene Design and Stage Lighting' (Wadsworth 2009, 2010, 2011). 2009 Helen Hayes Nominee (for Outstanding Set Design), a recipient of both the USITT Oren Parker Award for Excellence in Scene Design, and the 2007 Kennedy Center Design Fellowship.

Mikiko Suzuki Macadams Recent Credits includes: The Brothers Size, THe Glass Menagerie, and The Cook (Seattle Repertory Theatre), Its A Wonderful Life: a Live Radio Play (Long Wharf Theatre), Abe Lincoln in Illinois, and The Year of Magical Thinking(Intiman Theatre), Top Dog/Under Dog, and 9 parts of Desire (Actors Theatre of Louisville), Macbeth, Dispatches from (A)mended America, and Hold These Truth (Epic Theater Ensemble, Off Broadway), points of departure, kissing Fidel and TIght Embrace (INTAR Theatre, Off Broadway), Lenin's Embalmers and Pigeon (The Ensemble Studio Theatre, Off Broadway), Our Dad is in Atlantis (Working Theatre, Off Broadway), Low (The Public Theatre's Under the Radar Festival), Three Musketeers the musical (Nissei Theatre, Tokyo), Cavalleria Rusticana/Pagliacci (Nikikai Opera, Tokyo), The Mikado (Opera Theatre of St. Louise). Mikiko's work has been seen at Cornerstone Theatre Company, Cincinnati Playhouse, Yale Repertory Theatre, Brevard Music Center, New Jersey Opera, National Asian- American Thteatre, Yale Opera, among others. As an Associate Scenic Designer, Broadway credits include: Golden Boy, That Championship Season, Women on the Verge of a Nervous Breakdown, Next Fall and Joe Turner's Come and Gone, and for the US, 
UK and Australian national tour of Lincoln Center Theatre production of South Pacific.

Daniel Mueller is a freelance scenic, lighting and projections designer working out of New York City. Daniel received his master of fine arts from University of Memphis in scenic and lighting design. Most recently Daniel has been working with Broadway's Big Fish: The Musical as a video technichian.

Todd Rosenthal (Set Designer) received the 2008 Tony Award for August: Osage County and a 2011 Tony Award nomination for The Motherfu**er with the Hat. He designs on Broadway and at regional theaters across the country and abroad including: The National Theatre (London), Sydney Theatre Company (Australia), Manhattan Theatre Club, The Goodman Theatre, Steppenwolf Theatre Company, The Guthrie, Alliance Theatre, Oregon Shakespeare Festival, Theatre Royal (Ireland), Arena Stage, Berkeley Rep, Centerstage, Yale Rep, The Alley Theatre, Dallas Theater Center, Cincinnati Playhouse in the Park, Chicago Shakespeare, Barrow Street Theatre, Atlantic Theater Company, Lyric Opera of Chicago, Chicago Opera Theater and others. Recent/ upcoming designs: Roman Holiday, Born Yesterday and Nice Fish at the Guthrie; The Beauty Queen of Leenane, Theatre Royal Waterford, Ireland; August: Osage County, Sydney Theatre Company, National Theatre in London; Who's Afraid of Virginia Woolf, Broadway; Three Sisters, Clybourne Park, Steppenwolf Theatre; The Seagull, Goodman Theater; As You Like It, Oregon Shakespeare; Stephen King/ John Mellencamp's Ghost Brothers of Darkland County, Alliance Theater; A Parallelogram, The Mark Taper Forum, and Domesticated at Lincoln Center. Exhibitor, 2007 Prague Quadrennial. Lead designer for Mythbusters ${ }^{\mathrm{TM}}$, the Explosive Exhibition, and Sherlock Holmes, the Science of Deduction (exhibition). Designed sets for Big Apple Circus for five years. Awards: Tony Award, Lawrence Olivier Award, Los Angeles Times Ovation Award, Los Angeles Backstage Garland Award, Joseph Jefferson Award, Michael Merritt Award for Excellence in Design and Collaboration. Associate Professor, Northwestern University. Graduate, Yale School of Drama. toddar.com

Lisi Stoessel is a multidisciplinary theatre artist working in scenic design, puppetry, and performance. Lisi has studied painting, drawing, sculpture, and print making at the Maryland Institute, College of Art and at the University of Virginia's McIntire Department of Art, and holds her MFA in Scene Design from the University of Virginia. She has won a non-equity Jeff Award in Artistic Specialization for her robot design for Sideshow Theatre Company's Heddatron, as well as a UNIMAUSA scholarship to study marionettes in Prague with Mirek Trejtnar. She recently received a grant from the $\mathrm{CuDC}$ through the Creative Communities Fund to participate in Artistic Blind Dates for the 2012 Source Festival. Lisi is currently based in Washington DC, designing locally and abroad. She has had the pleasure of working with many talented artists, including Swim Pony Performing Arts, The Berserker Residents, Pig Iron Theatre Company, Philadelphia Shakespeare Theatre, Forum Theatre Company, Constellation Theatre Company, Sideshow Theatre Company, Johnny Showcase and the Lefty Lucy Cabaret, The Idiopathic Ridiculopathy Consortium, Inis Nua Theatre Company, The Heritage Theatre Festival, Adventure Theater, and Wits End 
Puppets. Lisi is a Field Artist and an Artistic Associate of Chicago's Sideshow Theatre Company. 